\title{
Interactive comment on "Hydraulic and geochemical impact of occasional saltwater intrusions through a submarine spring in a karst and thermal aquifer (Balaruc peninsula near Montpellier, France)" by Marie-Amélie Pétré et al.
}

\section{Ekkehard Holzbecher (Referee)}

ekkehard.holzbecher@gutech.edu.om

Received and published: 27 July 2020

The paper is an excellent study in which different methodologies (hydrogeological, physical and geochemical) and data are combined to obtained a coherent view of the system. I suggest few technical corrections, which I list here:

Line 94: Table 1, do not justify text within table cells

Line 272: Table 2, use centered format in all cells, including header 
Line 294: Table 3, do not justify text within table cells

Line 346: leave blanc between number and unit, $69 \mathrm{~m} \mathrm{~h}-1$

Line 368: Figure 5, the $2 \times 2$ sub-figure design extends outside of the page margins; as the reader may want to see the details, I suggest to put sub-figures a-d vertically in a $4 \times 1$ design

Interactive

comment

Line 450: use italics for ffresh and fsalt, in order to match with format in the equations Line 528: use italics for the f-factors, in order to match with format in equation 3

Interactive comment on Hydrol. Earth Syst. Sci. Discuss., https://doi.org/10.5194/hess-2020292, 2020. 